\title{
A Stereoselective Synthesis of C26-C36 Fragment of Arenicolide A
}

\author{
Jung Lyul Lee, Seo-Jung Han, and Duck-Hỵung Lee* \\ Department of Chemistry, Sogang Chwersit, Seoul 121-742. Korea. ${ }^{*}$ E-mail: dhlee ôsogang ackr \\ Recened Hay 7, 2009, Accepted Hav 21, 2009
}

Key Wonds: Arenicolide A, Anti-cancer activity. Stereoselective synthesis. Brown allylation. A ${ }^{1.3}$-strain

\begin{abstract}
Recently, arenicolides A (1) and B (2) were isolated from the large-scale fermentation of the S. arenicola strain CNR005 and its relative stereochemical relationship except $\mathrm{C}-12$. $\mathrm{C}-30$. and $\mathrm{C}-3 \mathrm{I}$ chiral centers was proposed by ${ }^{1} \mathrm{H}$ NMR.${ }^{13} \mathrm{C}$ NMR. Mass, IR. UV, CD, chemical degradation methods.' Arenicolides A (1) and B (2) are 26-membered macrolides with three conjugated dienes and nine chiral centers in the ring. There is one side chain which comprises the $\mathrm{C}-26 \sim \mathrm{C}-36$ carbon chain with five consecutive chiral centers. Arenicolide A (1) also showed moderate anti-cancer activity toward the human colon adenocarcinoma cell line HCT-116 (IC $\mathrm{ID}_{5} ; 30 \mu \mathrm{g} /$ $\mathrm{mL}$ ) and three cell lines in the National Cancer Institute. and no activity against antimicrobial assay using methicillinresistant $S$. aureus (MRSA) and vancomycinresistant $E$. faecium (VREF).
\end{abstract}

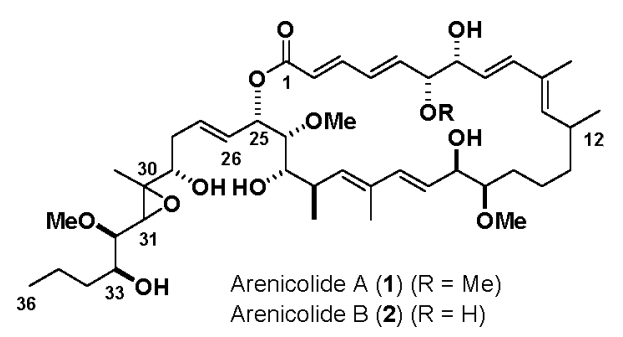

Arenicolide $C$ (3) was also isolated along with arenicolides $A$ (1) and $B$ (2). And we proposed that the cyclic ether moiety in 3 might be derived biologically from arenicolide $\mathrm{A}$ (1) via the acid-catalyzed opening of epoxide and $\mathrm{S}_{\mathrm{N}} 2$ type addition of the C.33 hydroxyl group. In this paper, we report the stereoselective synthesis of the plausible C-26 C-36 side chain (10) of arenicolide $\mathrm{A}(\mathbf{1})$ based on this assumption.

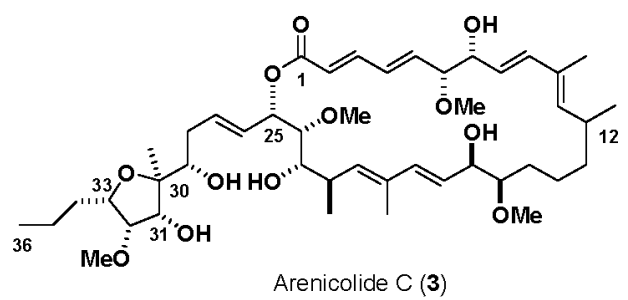

Retrosynthesis is summarized in Scheme 1. The homoallyl chiral center at C-31 of 4 would be introduced by asymmetric allylation of aldehyde. ${ }^{2}$ Conformational control from the allylic 1.3-strain and approach of the epoxidizing reagent anti to the methoxy group in $\mathbf{5}$ should provide the desired stereochemistry of $\dot{C}-30$ and $C-31$ epoxide in $4^{3}$ Finally, diastereoselective 1,2-sm aldol strategy of $\alpha$-methoyacetate moiety 6 would be used to construct the C-32 and C-33 chiral centers. ${ }^{4}$

The synthesis of target molecule $\mathbf{1 0}$ was summarized in Scheme 2. Evans-sm aldol reaction of $\alpha$-methoyacetate 6 with $n$-butanal provided the $1.2-5 n$ aldol product in $96 \%$ yield. $^{4}$ and the free $\beta$-hydrosyl group was treated by TBSOTf and 2.6 -lutidine to afford the TBS-ether 7 in $84 \%$ yield. The chiral auxiliany group of 7 was removed by reduction with $\mathrm{LiBH}_{4}$ in $94 \%$ yield. ${ }^{5}$ the resulting hydrosyl group was oxidized by Swern oxidation in $91 \%$. yield and the resulting aldehyde was treated with stabilized Wittig reagent to afford the $\alpha, \beta-$ unsaturated ester 8 in $92 \%$ yield. The ester group of 8 was reduced to primary alcohol by DIBAL in methylene chloride in $94 \%$ yield and the diastereselective epoxidation by $m \mathrm{CPBA}$ provided the desired epoxide 9 and its isomer in $72 \%{ }^{3}$ Swern

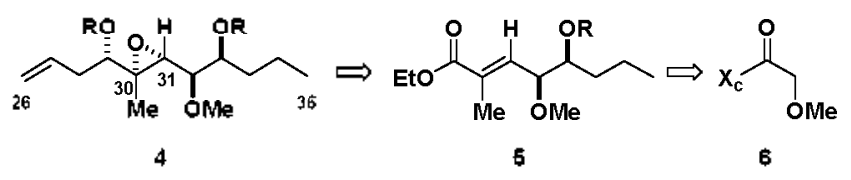

Scheme 1. Retrosynthesis

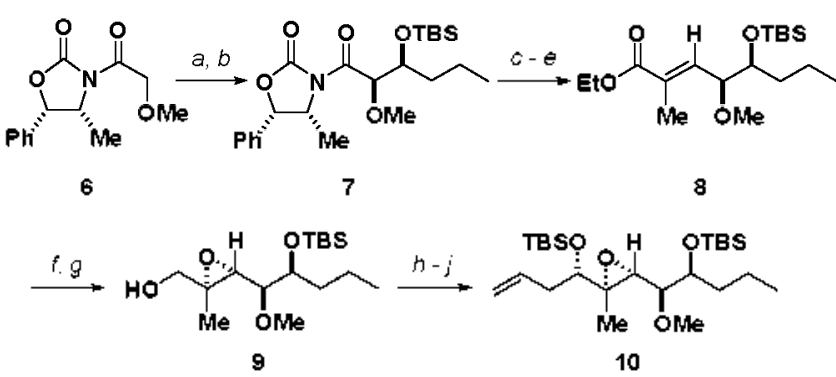

Scheme 2. Synthesis of C26-C 36 Fragment (4). (a) $n-B l_{2} \mathrm{BOTf}(1.5$ eq). $\mathrm{Et}_{3} \mathrm{~N}(1.6 \mathrm{eq})$, butyraldehyde $(2.0 \mathrm{eq}), \mathrm{CH}_{2} \mathrm{Cl} l_{2},-78{ }^{\circ} \mathrm{C}, 4 \mathrm{hr}, 96 \%$. (b) TBSOTf (1.2 eq), 2,6-lutidine (2.0 eq), $\mathrm{CH}_{2} \mathrm{Cl}_{2,}-78{ }^{\circ} \mathrm{C}, 3 \mathrm{hr}$, $84 \%$. (c) $\mathrm{LiBH}_{4}$ ( $1.12 \mathrm{eq}$ ), water (1.12 eq), ether, $\mathrm{rt}, 45 \mathrm{~min}, 94 \%$. (d) $(\mathrm{COCl})_{2}\left(2.5 \mathrm{eq}\right.$, DMSO (4.5 eq), $\mathrm{Et}{ }_{3} \mathrm{~N}(7.5 \mathrm{eq}), \mathrm{CH}_{2} \mathrm{Cl}_{2},-78^{\circ} \mathrm{C}, 1.5$ $\mathrm{hr}, 91 \%$. (e) $\mathrm{Ph}{ }_{3} \mathrm{P}=\mathrm{C}(\mathrm{Me}) \mathrm{CO}_{2} \mathrm{Et}(2.5 \mathrm{eq})$, benzene, reflus, overnight, $92 \%$ (f) DIBAL (5.0 eq), $\mathrm{CH}_{2} \mathrm{Cl}_{2},-78^{\circ} \mathrm{C}, 2 \mathrm{hr}, 94 \%$. (g) mCPBA (1.5 eq), $\mathrm{K}_{2} \mathrm{HPO}_{+}(3.0 \mathrm{eq}), \mathrm{CH}_{2} \mathrm{Cl}_{2}$, rt, $18 \mathrm{hr}, 72 \%$. (h) $(\mathrm{COCl})_{2}(2.0 \mathrm{eq})$, DMSO (4.0 eq). Et 3 N (5.0 eq), $\mathrm{CH}_{2} \mathrm{Cl}_{2},-78{ }^{\circ} \mathrm{C}, 40 \mathrm{~min}, 88 \%$. (i) (-) $\mathrm{Ipc}_{2} \mathrm{BOMe}(1.2 \mathrm{eq})$, ally magnesium bromide $(2.0 \mathrm{eq})$, ether, -100 ${ }^{\circ} \mathrm{C}, 3 \mathrm{hr}, 67 \%$. (j) TBSOTf (1.5 eq), 2,6-lutidine $(2.0 \mathrm{eq}), \mathrm{CH}_{2} \mathrm{Cl} \mathrm{l}_{2},-78$ "C, 30 min, $88 \%$. 
oxidation of primary alcohol 9 (88\%) and chiral-ligand assisted asymmetric ally lation of the resulting aldehy'de $(67 \%)^{2}$ produced the homoallylic alcohol with the correct stereochemistry at C-29 in $67 \%$ yield along with its isomer in $19 \%$ yield. Finally, protection of the secondary alcohol with TBSOTf and 2.6lutidine completed the sy nthesis of plausible $\mathrm{C}-26 \sim \mathrm{C}-36$ side chain moiety (10) of arenicolide A (1).

The origin of diastereoselectivity in the epoxidation reaction can be rationalized by conformational preferences of conformation $\mathbf{A}$ over conformation $\mathbf{B}$ due to the $A^{1.3}$-strain. ${ }^{6}$ In addition, hydroxyl-group directed epoxidation and $a n t i$-periplanar approach of the electrophilic oxygen to the best $\sigma$ electron acceptor (methoxy group) ${ }^{8}$ clearly lead to the desired stereochemistry in 9 through the assembly A-1 over the A-2.

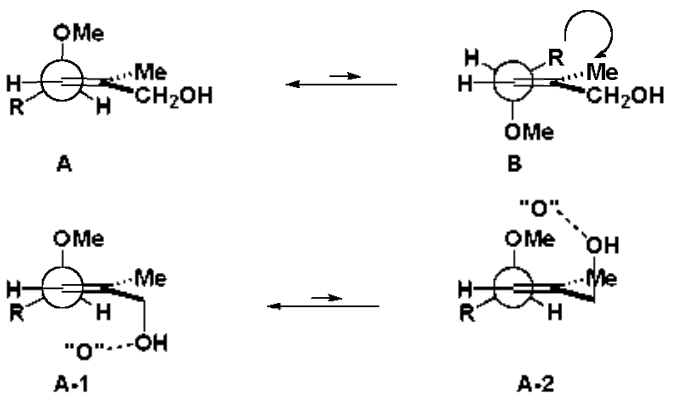

In order to further confinm the relative stereochemical relationship of epoxide 9. the primary hydroxyl group of 9 was converted to the benzyl ether by treatment with sodium hydride and benzyl bromide in THF in $91 \%$ yield and the TBSether was deprotected by TBAF in THF to give the secondary alcohol 11 in $63 \%$ yield. After conversion of the secondary alcohol 11 to carbamate 12 by reaction with dimethỵ lcarbamyl chloride in $87 \%$ yield. Intramolecular $\mathrm{BF}_{3}$-assisted epoxideopening and cyclization were carried out in methylene chloride to afford the cyclic carbonate 13 in $52 \%$ yield. ${ }^{6}$ NOE experiment of 13 confirmed the relative stereochemistry of 13 and therefore that of 9 . an intermediate in the synthesis of target molecule 10 .

In summary, the plausible C-26 C-36 side chain 10 of arenicolide $A$ ( 1 ) was prepared concisely and efficiently in 10 steps. The key steps are Evans 1.2-sy aldol reaction diastereoselective epoxidation and asy mmetric allỵlation of aldehyde.

Acknowledgments. This research was assisted financially by Korea Science and Engineering Foundation (KOSEF) (2008-0058780 and 2009-0058780). BK21 graduate fellowship grant to J. L. Lee and S. J. Han is gratefully acknowledged. The instrument facilities of the Organic Chemistry Research Center (OCRC) in Sogang University were also helpful.
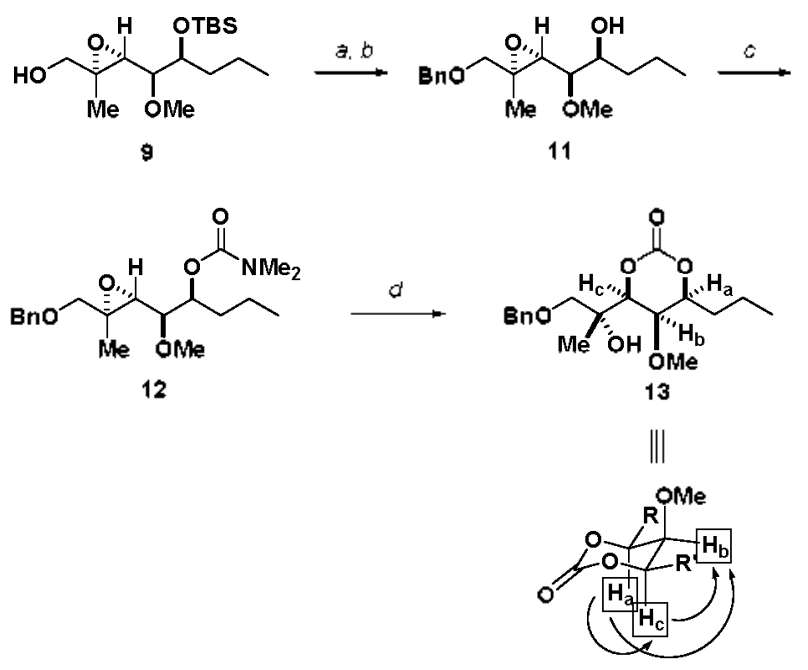

Scheme 3. Confimation of relative stereochemistry of epoxide 9. (a) $\mathrm{BnBr}(1.10 \mathrm{eq}), \mathrm{NaH}(1.10 \mathrm{eq}), n-\mathrm{Bu}+\mathrm{NI}(0.40 \mathrm{eq}), \mathrm{THF}, \mathrm{rt}, 3 \mathrm{lh}, 91 \%$. (b) TBAF (2.5 eq). THF, rt, $3.5 \mathrm{hr}, 63 \%$. (c) Dimethylcarbamyl chloride ( 1.5 eq), $\mathrm{NaH}$ (1.2 eq), DMAP (0.3 eq), DMF, rt, 8 hr, $87 \%$.

(d) $\mathrm{BF}_{3} \circ \mathrm{OEt}_{2}(\mathrm{l} .6 \mathrm{eq}) \mathrm{CH}_{2} \mathrm{Cl}_{2}, \mathrm{rt}$, overnight, $52 \%$.

\section{Refeiences}

1. (a) Williams, P. G.; Miller, E. D.: Asolkar, R. N.: Jesen, R. R.; Fenical, W. J. Org. Chemt 2007, 72, 5025-5034.

2. Brown, H. C. Jadhav, P. K. J. Am. Chem. Soc. 1983, 105, 2092-2093

3. (a) Jung, M. E.; D Amico, D. C. J. Am. Chem. Soc. 1997, 119, 12150-12158. (b) Saito, S.; Itoh, H; Ono, Y; Nishioka, K.; Moriwake, T. Tetrahedron Aspmmetry 1993, 4, 5-8.

4. Evans, D. A.; Bartroli, J.; Shih, T. L. J. Ant. Chent. Soc. 1981, $103,2127-2129$

5. Evans, D. A.; Nagony, P, Reynolds, D. J.: McRae. K. I. Angew: Chem. Int Ed. 2007, +6, $541-544$.

6. (a) Rossiter, B. E.: Verhoeven, T. R.: Sharpless, K. B. Tetrahedron Letter 1979, 20,4733-4736. (b) Tomioka, $\mathrm{H}$; Suzuki, T: Oshima, $\mathrm{K}$; Nozaki, H. Tetwhed won Letter 1982, 23, 3387-3390.

7. Henbest, H. B.; Wilson, R. A. L. J. Chem. Soc. 1957, 1958-1965.

8. (a) Wul, Y. D.: Tucker. T. A.; Houk, K. N. J.tm. Chem. Soc. 1991 , 113,5018-5027. (b) Paddon-Row, M. N.: Rondan, N. G.: Houk, K. N. J.Am Chem. Soc. 1982, 104, 7162-7166.

9. (a) Kutsumura, N.; Nishiyama, S. Tetrahed hon Letter 2005, t6, 5707-5709. (b) Bravo, F; McDonald, F. E; Neiwert, W. A.; Do, B.: Hardeastle, K. I. Oig. Lett. 2003, 5, $2123-2126$.

10. $[\alpha]_{D}=+11.2(c=0.0017 \mathrm{MeOH})$; ${ }^{1} \mathrm{H} N \mathrm{NMR}\left(\mathrm{CDCl}_{3}, 500 \mathrm{MHz}\right) \delta$ $5.86 \sim 5.81(\mathrm{~m}, \mathrm{lH}), 5.10 \sim 5.03(\mathrm{~m}, 2 \mathrm{H}), 3.78 \sim 3.74(\mathrm{dd}, \mathrm{lH})$, $3.38(\mathrm{~s}, 3 \mathrm{H}), 3.29 \sim 3.27(\mathrm{dd}, \mathrm{lH}), 2.93 \sim 2.90(\mathrm{~m}, 1 \mathrm{H}), 2.84 \sim$ $2.82(\mathrm{~d}, \mathrm{lH}), 2.45 \sim 2.40(\mathrm{~m}, \mathrm{lH}), 2.33 \sim 2.29(\mathrm{~m}, \mathrm{lH}), 1.66 \sim$ $1.64(\mathrm{~m}, 2 \mathrm{H}), 1.50 \sim 1.47(\mathrm{~m}, 2 \mathrm{H}), 1.35(\mathrm{~s}, 3 \mathrm{H}), 0.90(\mathrm{~s}, 9 \mathrm{H}), 0.88$ $(\mathrm{s}, 9 \mathrm{H}), 0.087(\mathrm{~s}, 3 \mathrm{H}), 0.079(\mathrm{~s}, 3 \mathrm{H}), 0.059(\mathrm{~S}, 3 \mathrm{H}), 0.035 \mathrm{~s}, 3 \mathrm{H})$ : ${ }^{3} \mathrm{C}$ NMR $\left(\mathrm{CDCl}_{3}, 125 \mathrm{MHz}\right) \delta 135.276,117008,80.291$, $76.892,74.172,60.052,58.558,39.179,35.752,26.227,26.022$, $13.352,-4.239,-4.287 ;$ IR (neat) $2949,2930,2857,1470,1378$, $1243,1104,914,831,779,660 \mathrm{~cm}^{-1}$. HRMS (ESI) calculated for $\mathrm{C}_{24} \mathrm{H}_{32} \mathrm{O}_{4} \mathrm{Si}_{2}[\mathrm{M}+\mathrm{Nal}]^{-} \mathrm{m} / \mathrm{z} 495.3301$, found 495.3305 . 